
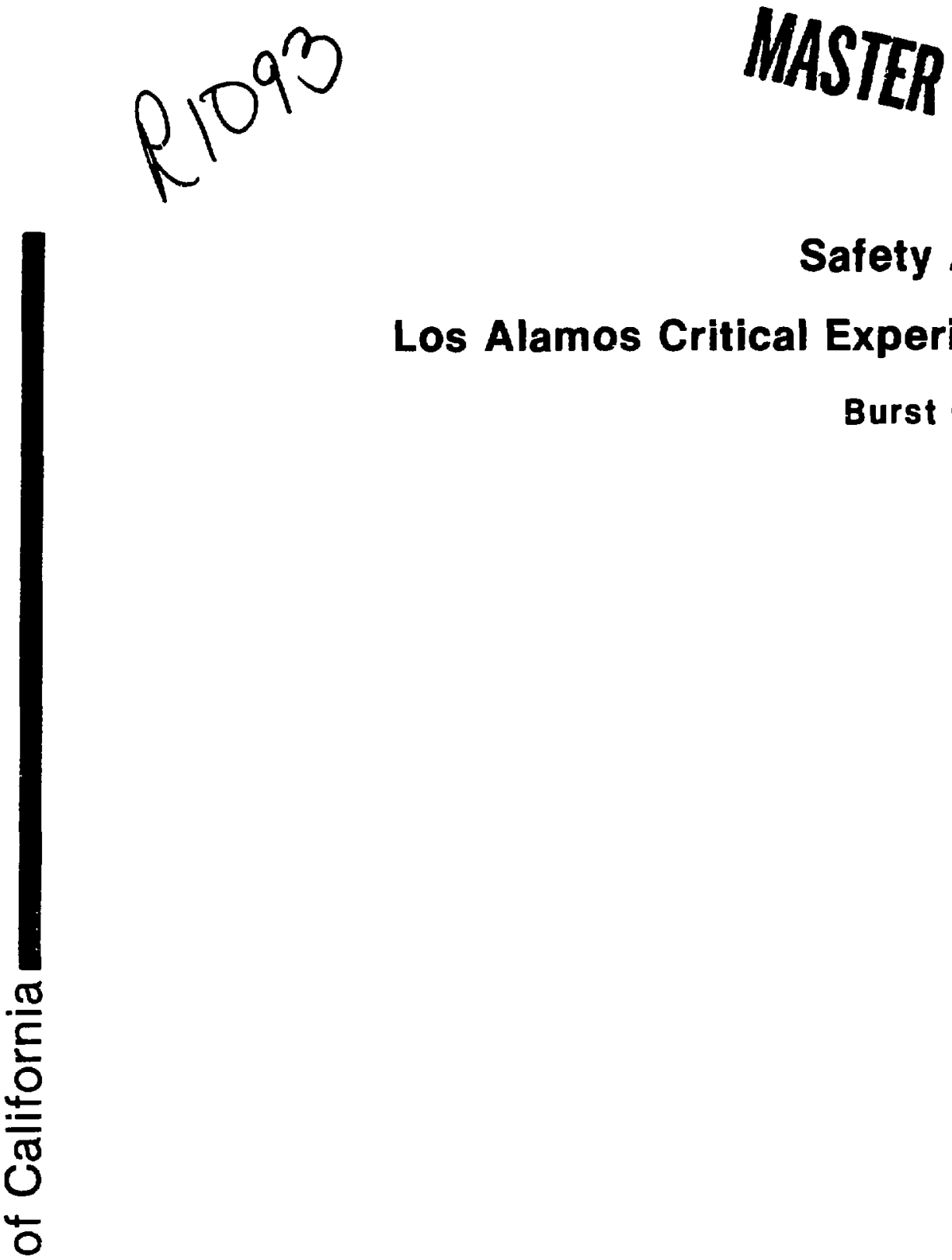

\title{
Los Alamos Critical Experiments Facility: \\ Burst Operation of Skua \\ Safety Analysis of the
}




\section{CONTENTS}

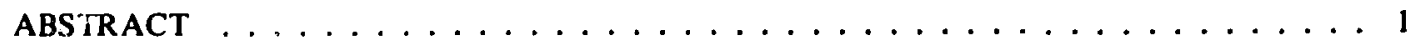

1. INTRODUCTION AIND GENERAL DESCRIPTION OF THE FACILITY . . . . . . 1

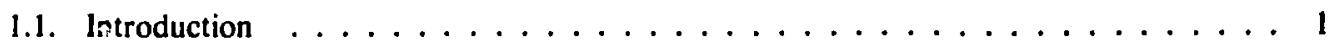

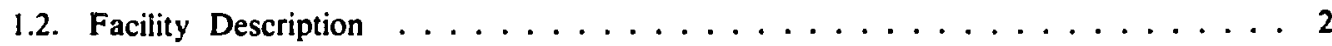

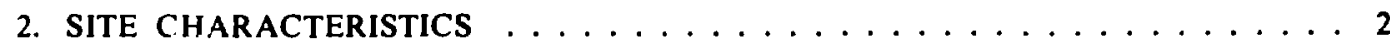

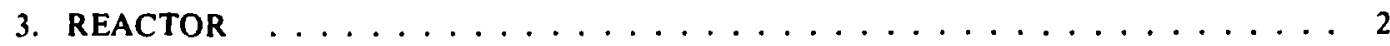

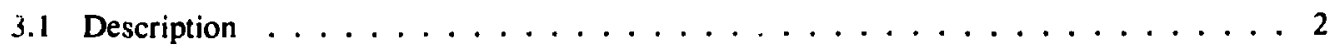

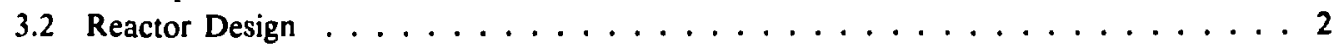

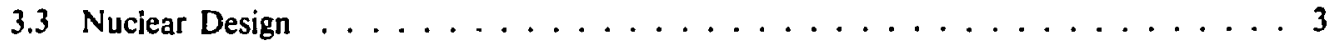

3.4 Thermal and Hydraulic Design $\ldots \ldots \ldots \ldots \ldots \ldots$

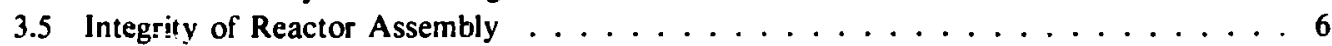

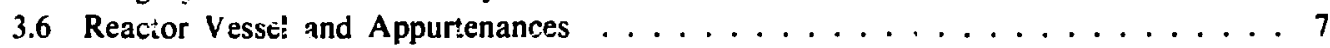

3.7 Components and Subsystem Desigin . . . . . . . . . . . . . . 7

3.8 Instrumentation Application $\ldots \ldots \ldots \ldots \ldots \ldots \ldots$

4. ENGINEERED SAFETY FEATURES $\ldots \ldots \ldots \ldots \ldots \ldots \ldots$

5. INSTRUMENTATION AND CONTROLS $\ldots \ldots \ldots \ldots \ldots \ldots$

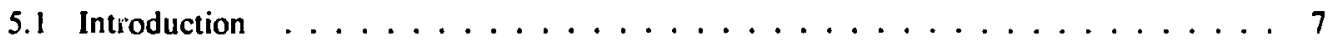

5.2 Reactor Trip System . . . . . . . . . . . . . . . . . 8

5.3 Engincered Safety Systems . . . . . . . . . . . . . . . . . 9

5.4 Systems Required for Safe Shutdown ... . . . . . . . . . . . 9

5.5 Safety-Related Display Instrumentation . . . . . . . . . . . . . 9

5.6 All Other Systenss Required for Safety . . . . . . . . . . . . . . . 9

5.7 Control Systems . . . . . . . . . . . . . . . . . 9

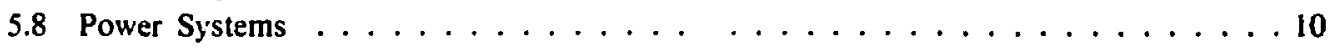

6. AUXILIARY SYSTEMS $\ldots \ldots \ldots \ldots \ldots$

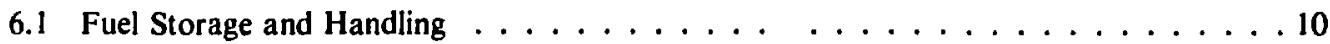

6.2 Fire Protection System $\ldots \ldots \ldots \ldots \ldots \ldots \ldots$

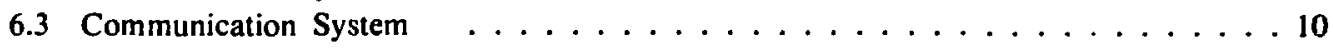

7. EXPERIMENTS: DESCRIPTION AND PURPOSE $\ldots \ldots \ldots \ldots \ldots \ldots$

8. RADIOACTIVE WASTE MANAGEMENT $\ldots \ldots \ldots \ldots \ldots \ldots \ldots$

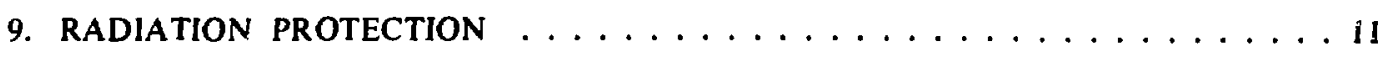

10. PROCEDURES FOR BURST PRODUCTION $\ldots \ldots \ldots \ldots \ldots \ldots \ldots$ 


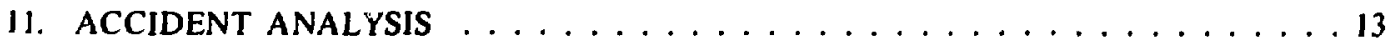

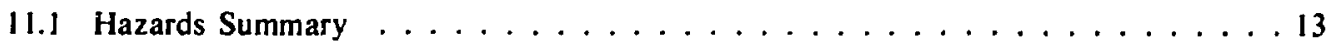

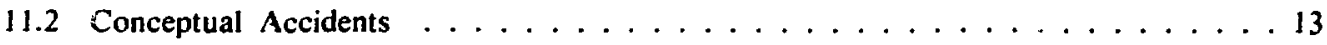

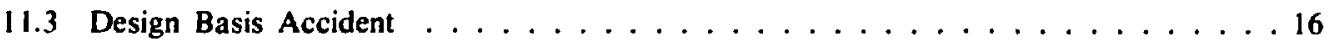

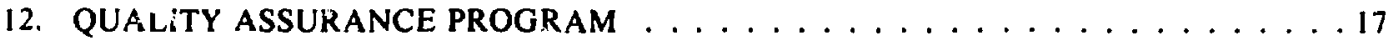

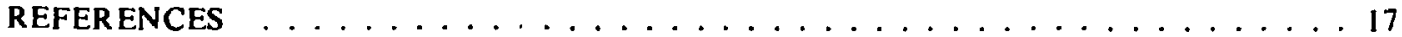

Approved:

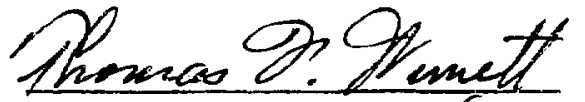

For Q-14 Safety Committee
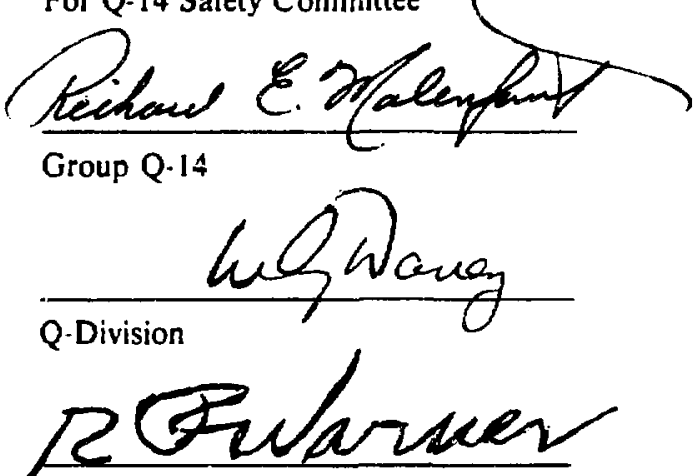

For LASL Reactor Safety Committee

vi 


\title{
SAFETY ANALYSIS OF THE LOS ALAMOS CRITICAL EXPERIMENTS FACILITY: BURST OPERATION OF SKUA
}

by

\author{
J. D. Orndoff, H. C. Paxton, and T. F. Wimett
}

\begin{abstract}
This report provides detailed consideration of the Skua burst assembly, thereby supplementing the facility Safety $A$ ialysis Report covering the operation of other critical assemblies at the Los Alamos Scientific Laboratory. As with these assemblies the small fission-product inventory, ambient pressure, and moderate temperatures in Skua are amenable to straightforward measures to ensure the protection of the public.
\end{abstract}

\section{INTRODUCTION AND GENERAL DESCRIP. TION OF THE FACILITY}

\section{I Introduction}

Los Alamos Scientific Laboratory (LASL) critical assemblies are presently covered by a facility Safety Analysis Repon (SAR), LA-6206, Vols. I and Il.' A separate SAR (LA-4797-MS) ${ }^{2}$ for a recently discontinued assembly, "Kinglet," is incorporated by reference. The facility report is augmented by Experimental Plans, which describe in detail the special features of each assembly and present discussions of the safety of planned experiments. Sequential Experimental Plans are written as assemblies are modified and experiments are developed. In this manner the SAR is effectively kept up-to-date without much repetitive documentation.

This addendum is written because Skua has certain features that distinguish it from previous systems, and operations in the burst mode are more sensitive (as in Godiva) than the normal experiments near delayed criticality. In Skua an annular metal assembly, with a polyethylene or zirconium hydride flux trap inside, is intended for fast-burst operation. We will approach any unproven operations in the same way as those with previous assemblies; namely, through a series of steps and a series of Experimental Plans, each of which takes advantage of previous experience. Because preliminary critical experiments have been completed, precise information is already at hand concerning Skua's neutronic characteristics.

This SAR has been directed at the "large" flux-trap systems, which result in extreme thermal neutron flux at the center. Specifically, the system that was explored in the preliminary critical experiments is the one considered here for burst operation analysis. At some stage in the history of Skua, it will be desirable to modify the central neutron flux spectrum by adjusting the content of the flux-trap moderator so that neutronics of the potential systems of interest will vary from that of the metal fast-burst reactor (Godiva, Super Kukla, SPUR, etc.) to that of the flux-trap geometry considered here. (In this addendum other versions of Skua are not considered in detail.) Variations in flux-trap geometry will be covered by an Experimental Plan, and critical experiments will be conducted to establish neutronic characteristics before burst operation. Behavior and operation of Skua without a flux trap are not significantly different from Godiva.

The original concept of this burst reactor grew out of work in LASL Group J-10 involving a program to study atmospheric phenomena. The reactor was $t c$ be used for rapid vaporization of $100 \mathrm{~g}$ of ${ }^{233} \mathrm{U}$ in a highly oxidizing 
atmosphere. The reactor may therefore be used to vaporize various compounds that are enriched in ${ }^{235} U$.

\subsection{Facility Description}

The facility insofar as it relates to Skua operation is adequately described in LA.6206.' Skua is located at Pajarito Site (TA-18) in Kiva 3 along with Godiva IV and PARKA. This Kiva differs from the other two in that $0.46-m$-thick concrete walls provide about an order-of-magnitude radiation shielding, which nore than compensates for Kiva 3 being closer to occupied buildings than are the other two Kivas. This shielding also permits access to the outside of the Kiva shortly after high-level operation.

\section{SITE CHARACTERISTICS}

Site characteristics are presented in LA-6206. ${ }^{1}$ The interaction of Skua with the site is similar to that of the other critical assemblies at Pajarito Site.

\section{REACTOR}

\subsection{Description}

Skua consists of stacked U(93)-93\% enrichedrings reflected by copper on the outer radius and at the ends. An annular, hydrogenous flux trap inside the fuel rings generates an intense thermal neutron flux in an irradiation cavity at the center. The flux trap may use either zirconium hydride or polyethylene $\left(\mathrm{CH}_{2}\right)$ to moderate the high-energy fission neutrons.

The Skua assembly and actuating machinery are mounied on a $51 \cdot \mathrm{mm}$-thick aluminum plate supported by four support legs of 127 -mm-diam hollow steel pipe. Three safety blocks consist of 76-mm-thick copper reflector segments. which are driven radially by hydraulic cylinders. Three rotary, copper reflector cylinders act as control elements, one of which is driven hydraulically to act as a burst drum; the other two are rotated by electric motors.
The machine power circuit, hydraulic system, and scram chain logic are typical of the other Pajarito Site assemblies as described in the facility SAR.

\subsection{Reactor Design}

The Skua critical assembly machine is shown in Fig. 3-1, vertical and horizontal cross-sectional views are shown in Fig. 3-2, and a detailed cutaway view is shown in Fig. 3-3. The fuel ring composition is the same U-Mo ( $1.5 \mathrm{wt} \%$ ) alloy used in Godiva IV. Twelve fuel rings are available. In the initial configuration these were $0.318-\mathrm{m}$ o.d. ( 12.5 in.), $38 \mathrm{~mm}$ (1.5 in.) in annular thickness, and $25 \mathrm{~mm}$ ( 1 in.) in axial thickness. The dimensions shown in the fuel ring cross-sectional drawing of Fig. 3-4 are the present dimensions after remachining. Detail of the flux-trap composition is shown in Fig. 3-5. The cadmium, boral (boron-aluminum), and uranium-loaded graphite slceves. indicated in the diagram, absorb low-energy neutrons from the flux trap to avoid excessive

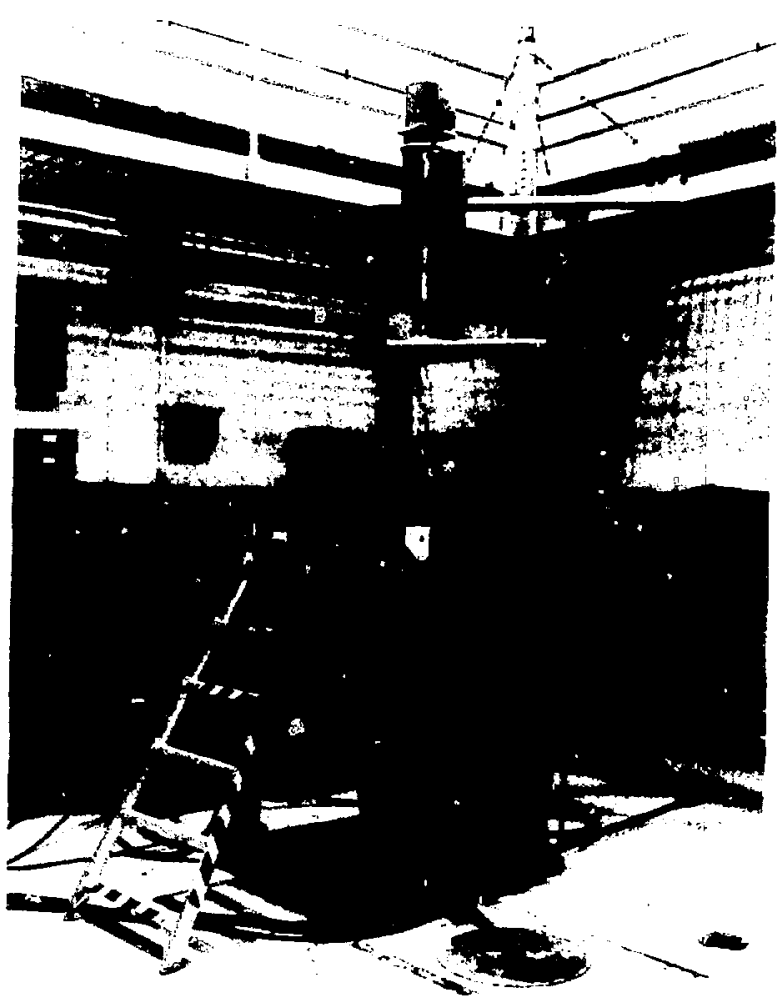

Fig. 3.1.

Skua in Kiva 3. 

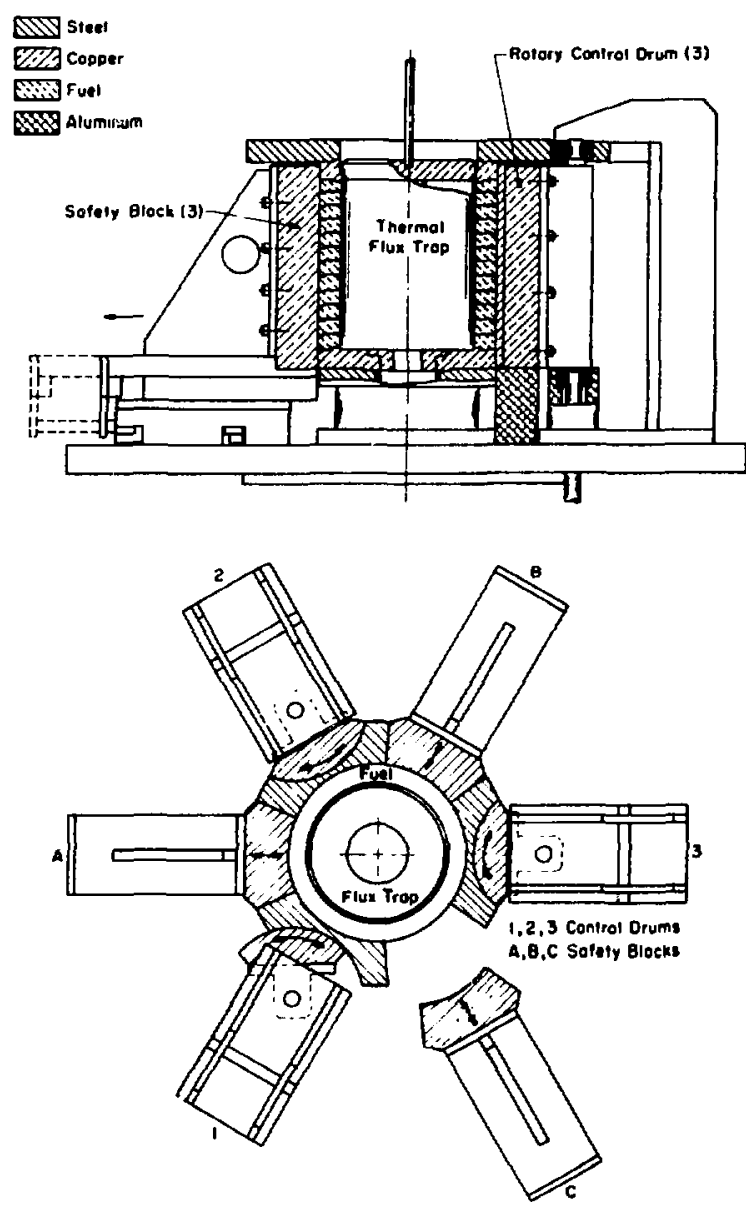

Fig, 3.2.

Cross-sectional views of Skun.

fission peaking in the uranium rings. The entire flux trap is encased in an aluminum can. A cylindrical irradiation cavity at the flux-trap center is $76 \mathrm{~mm}$ in diameter. Both zirconium hydride and polyethylene components are available for use in the flux trap as the moderator.

\subsection{Nuclear Design}

Early calculations on Skua assumed a reflector of beryllium, because beryllium combines light weight with good nuclear properties. Later, beryllium was rejected in favor of copper to eliminate preinitiation of bursts by $(\gamma, n)$ neutrons in beryllium and to avoid long neutron lifetimes associated with neutron slowing-down time in the reflector. Copper appears to be the best reflector material, per unit volume, of various candidate metals. The reflector functions primarily as a means of control. In addition, it plays a useful role in isolating the reactor from the reactivity effects of external objects. Quenching in fast-burst reactors results principally from the reactivity change associated with expansion and consequent density reduction of fuel as the temperature increases. Reflection reduces the quenching action, so it is important that the reflector not be too effective. As quenching is reduced, burst width is increased for a fixed energy release.

Flux traps using hydrogen as a moderator may introduce large reactivity contributions, either positive or negative, depending upon the moderator-absorber composition. The most effective flux trap in Skua introduces many dollars worth of poison. The uranium carbide annulus surrounding the flux irap fulfills three functions: (a) it adds reactivity in order to balance, in part, the negative reactivity resulting from the hydrogenous flux trap: (b) it absorbs low-energy neutrons from the flux trap and along with the boron and cadmium serves to eliminate any fission spike near the surface of the uranium metal rings; and (c) it serves as a thermal barrier between the uranium rings and the flux trap. The most important of the three functions is that of adjusting the reactivity of the flux-trap assembly. The other functions are usefui but not essential. Reactivity can be adjusted either by varying the loading in the uranium carbide sleeve or by varying its thickness, thereby, allowing for shimming the reactivity of the system without machining the uranium metal rings or adding additional sections. Uranium in the sleeve and in the fuel rings is enriched to $93 \%$. Varying the amount of uranium to obtain desired reactivity levels will not significantly affect the burst characteristics of Skua.

The $s$. ss of the uranium rings fabricated for Skua were determined by transport calculations of the system. The annular thickness was fixed conservatively so that the final shimming in reactivity could be done by remachining the inside or outside of the rings.

Initial critical operations have confirmed the Skua design. We attained criticality with a stack of 10 of the 12 possible fuel rings. We then replaced the eighth fuel ring with a depleted uranium substitute and were able to complete the fuel stack and obtain a critical configuration with one control drum at $35^{\circ}$ (where $0^{\circ}$ is "in"). We adjusted reactivity to the desired level by machining material from the fuel rings, permitting the depleted uranium ring to be replaced by a $U(93)$ ring. 


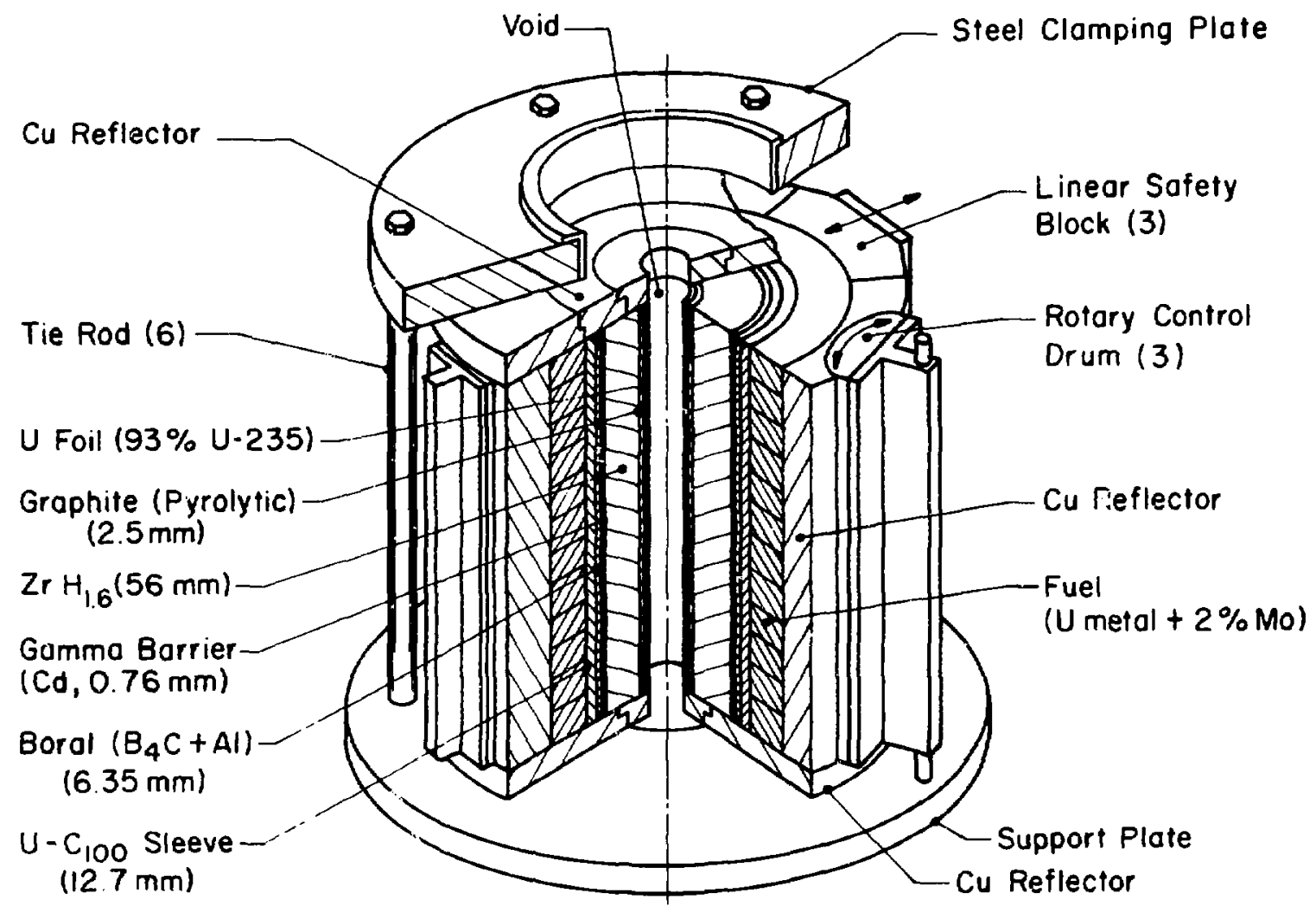

Fig. 3.3.

Skua critical components.

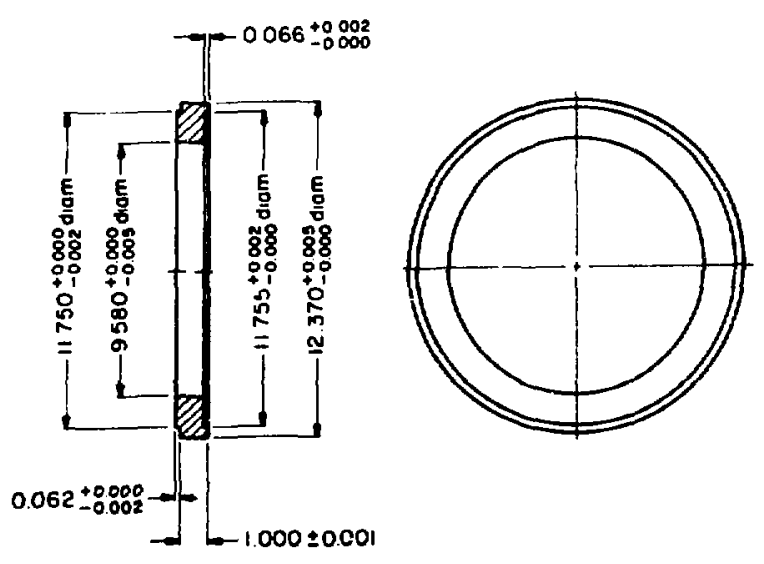

Dimensions in inches

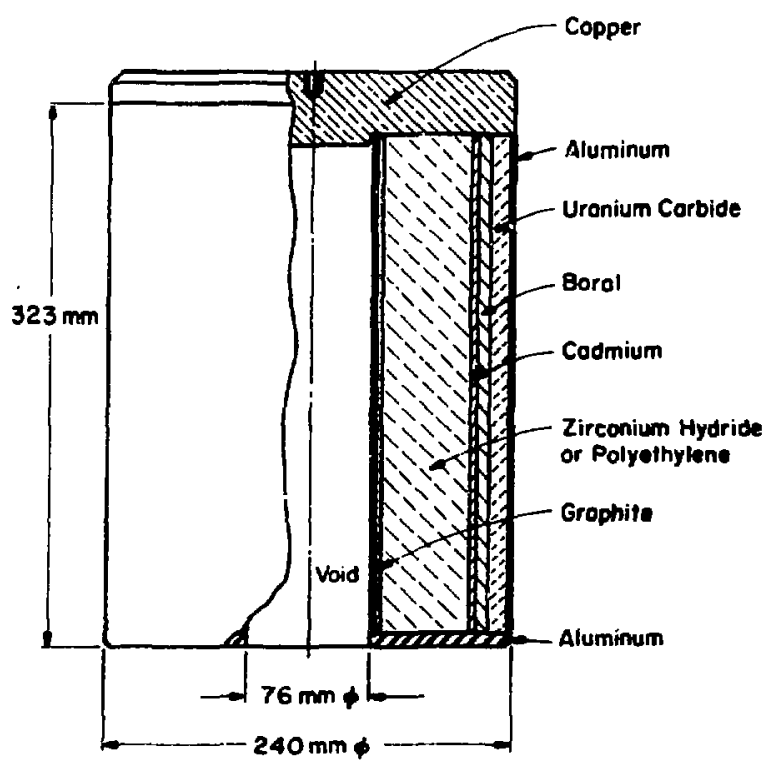

Fis. 3.5.

skun thex trap.
Fis. 3.4.

Skua fuel ring 
Measurement of reactivity worths of the various copper reflector controls roughly confirmed predictions by TWOTRAN calculations. Total shutdown by the three safety blocks is $9.9 \mathrm{~S}$, which is well in excess of the $5 \mathrm{~S}$ required by "Technical Specifications for the Pajarito Site Critical Experiments Facility."3 The rotary vernier control-drum worth curve, plotted in Fig. 3-6, was obtained by first adding reactivity with the drum being measured and then removing reactivity with the other identical control, so the resulting curve may be influenced by interaction between the drums. Torth of a single safety block is shown in Fig. 3-7 as a function of position. We made criticality measurements with the central flux trap "in" and "out" for bsth zirconium hydride and polyethylene moderator cumponents. The components are identical in size, but hydrogen density is higher in the polyethylene. The zirconium hydride flux trap acted as a poison of $\sim 6 \$$ in reactivity, and with polyethylene the flux trap acted as a poison of $\sim \mathbf{8} \mathbf{\$}$.

TWOTRAN calculations were run to estimate the neutron lifetime in the Skua geometry with a zirconium hydride flux trap. The computed value for the prompt

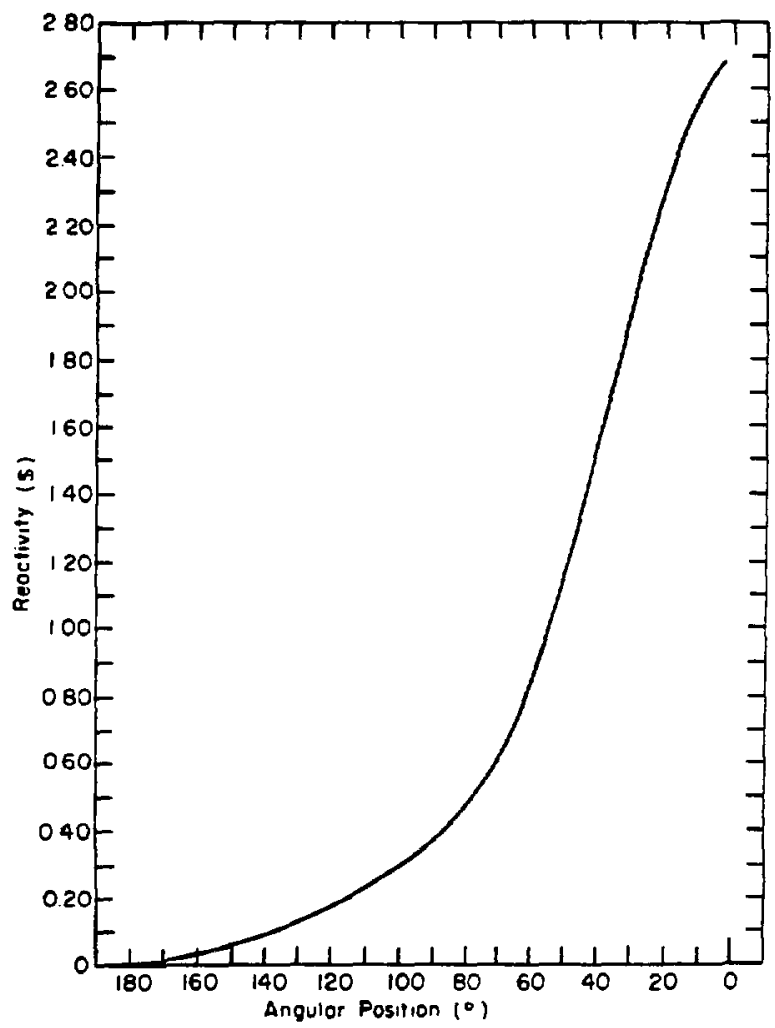

Fig. 3.6.

Skua conirol-drum worth.

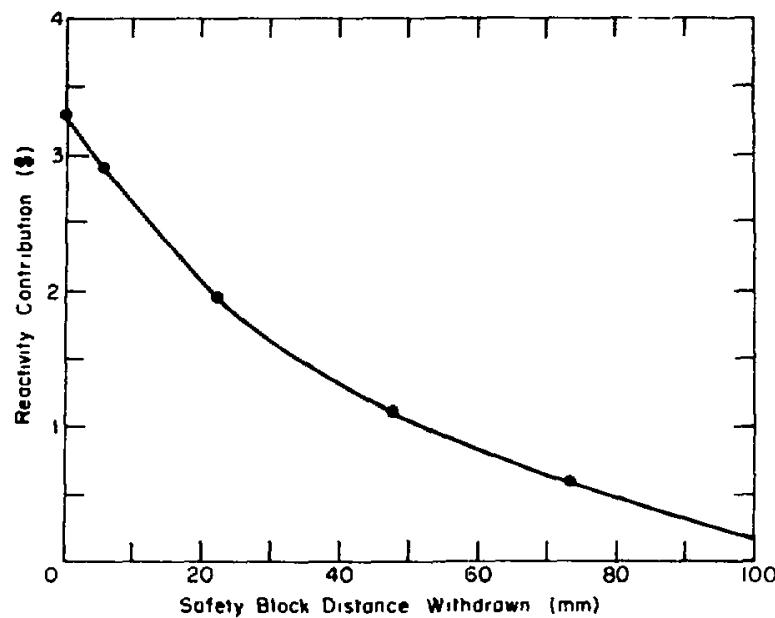

Fig. 3.7.

Skua safety-block worth.

neutron lifetime is $5 \times 10^{-8} \mathrm{~s}$, obtained by evaiuating $\mathrm{dk} / \mathrm{d \alpha}$. The value is an order of magnitude longer than for Godiva IV and leads to correspondingly longer prompt burst widths in Skua. The expected reduction in quenching resulting from the presence of the Skua reflector will broaden the bursts even more. On the basis of present knowledge. we expect the radiation pulse widths from the most energetic Skua bursts to be $\sim 1 \mathrm{~ms}$ wide.

\subsection{Thermal and Hydraulic Design}

No special cooling following bursts is planned for Skua other than external fans, even though the fuel rings will reach temperatures as high as $500^{\circ} \mathrm{C}$ during the most intense bursts. As is the case with Godiva, the burst repetition rate will be limited by cocl-down time. A, Ir flow directed to the accessible regions of Skua is :elatively ineffective in reducing the temperature of the fuel. Possible energy depositions and associated ' emperatures for an intense burst have been computes for a Skua geometry throughout the assembly and are illustrated in Fig. 3-8. The $110^{\circ} \mathrm{C}$ temperature increase shown for boral will be reduced considerably in the present design, which employs a cadmium barrier inside the boral. The central irradiated-uranium-foil thickness was $0.3 \mathrm{~mm}$ for the calculation.

Temperature rise in the fuel rings provides a fundamental measurement of burst yield in Skua. Knowledge of the fission distribution in the fuel allows the yield 


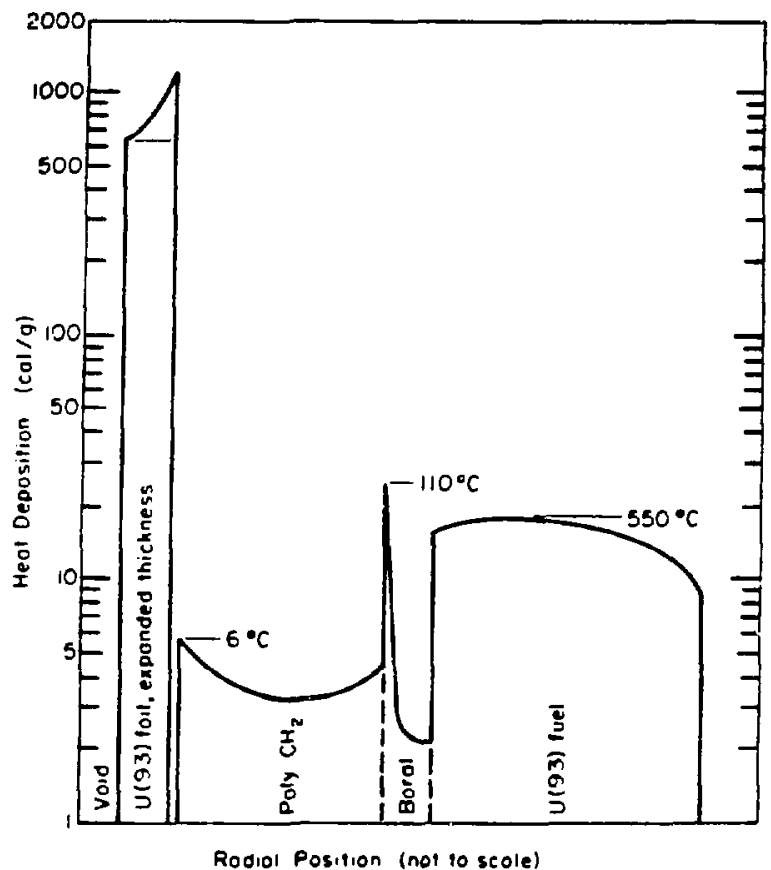

Fig. 3.8.

Computed heat deposition and temperature rises in Skua.

to be related to a single thermocouple reading, as has been donc with Godiva. One or more Chromel-Alumel thermocouples located in the fuel rings will provide the basic yield measurement for Skua bursts. (This instrumentation has been repeatedly checked out in Godiva.) The temperature measurement is important in obtaining reproducible yields, because any temperature change between the time that reactivity is checked and the time of the burst must be taken into account. These changes are not large enough, however, to constitute a significant hazard.

\subsection{Integrity of Reactor Assembly}

The discussion of integrity in LA- $6206^{1}$ is applicable to Skua. Strengths of materials are, in general, not a problem with our small critical assemblies, because the supports and structures are greatly over-designed for strength. The drawing of the Skua support stand in Fig. 3-9 shows this typical conservatism. The most critical component in Skua is the burst drum, which must be rotated rapidly into its most reactive position. It is important that the final position of the burst drum in

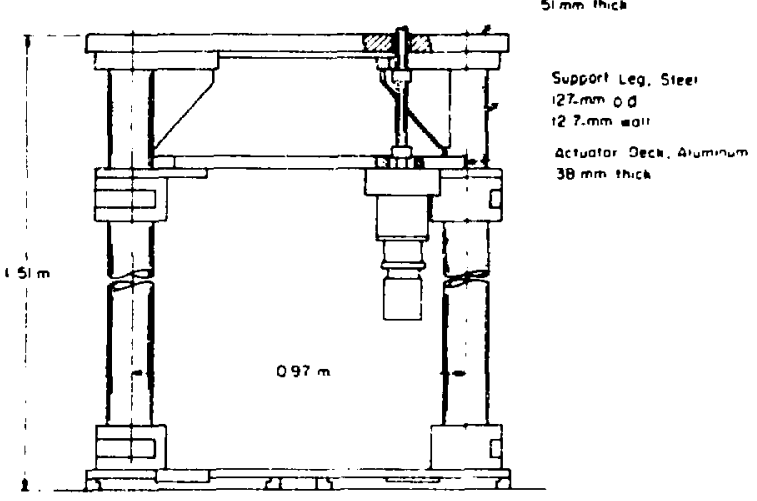

Fig. 3.9.

Skua support stand.

initiating a burst be identical to that during the preceding reactivity check. A mechanism has been designed to move the burst drum into position accurately with the requisite speed and without oscillation. Spesific checks of the proper operation of the burst drum will be carried out before burst operation.

The $1.5 \%$ U-Mo alloy used for the fuel in Skua was produced initially for testing in Godiva IV. We hoped that this alloy would be less susceptible to surface oxidation than pure uranium; we added the molybdenum for this reason and not to change the physical or the mechanical characteristics. We do not expect the low-molybdenum alloy to differ significantly from pure uranium in its physical properties. No attempt has been made to phase stabilize the Skua alloy. The material as cast at LASL is fine-grained, alpha phase in structure, with no significant orientation; hence, it expands uniformly with temperature. In Godiva IV the material proved to be stable with regard to temperature cycling, and there is no reason to expect that a different alloy would be more desirable as Skua material. Grain-size and phase changes are not expected unless temperatures exceed $\sim 400^{\circ} \mathrm{C}$. In any case, phase changes would decrease the density of the alloy and thereby decrease reactivity. The 10\% U-Mo alloy used for burst reactors at other installations is stabilized in the gamma phase to provide isotropic properties resulting from the gamma-phase cubic crystal structure. Higher strength (but lowered ductility) is obtained with the gamma phase than with the homogeneous alpha-phase material.

Skua rings were inspected for dimensional tolerance and weight, and radiographs showed that voids and 
inclusions would not significantly affect their strength or nuciear properties. Samples from each ring were analyzed chemically for impurities and tested with a mass spectrometer for isotopic enrichment. In all cases the rings were within specifications and tolerances.

\subsection{Reactor Vessel and Appurtenances}

No reactor vessel is used with Skua. A container to confine oxidized uranium dust was installed on Godiva, but it was essential only when the intermetallic aluminum coating applied to the surface was defective. With properly coated fuel rings, dispersal of oxide should not be a problem. If necessary, an enclosure to confine dust will be used.

\subsection{Components and Subsystem Design}

The discussion of component and subsystem design in LA-6206' is applicable to Skua. The machine power circuit logic provides power to the Skua assembly by a relay at the Kiva as shown in Fig. 3-3(A) of Vol. 11 in the above reference.

The hydraulic power package energizing the Skua actuators is a standard unit oi a type used with other Pajarito Site assemblies. Three nitrogen gas accumulators are incorporated for pressure back-up to assure that the system is fail-safe in case of hydraulic pump or power failure. The accumulators operate independently for each safety block.

\subsection{Instrumentation Application}

See Sec. 5 for descriptions of the standard Kiva instrumentation used with Skua and the specialized instrumentation used (a) to provide a signal for fast scram, (b) to measure the prompt period for a check on reactivity, and (c) to display the overall burst shape on an oscilloscope.

\section{ENGINEERED SAFETY FEATURES}

The discussion of engineered safety features in LA-6206' is applicable to Skua.

\section{INSTRUMENTATION AND CONTROLS}

\subsection{Introduction}

The discussion of instrumentation and controls in LA-6206' ${ }^{1}$ is applicable to Skua. In addition to that report. specific instrumentation requirements for burst operation are identified in Sec. 3.8 of this report. The instrumentation is identical to that used with Godiva for the same purpose and hence has undergone extensive development and testing. A neutron source is not normally used with a bursi machine; in fact, a significant source will cause preinitiation and reduced and erratic burst yield. Thus, there is no mechanism for handling a source.

As with Godiva it is important to provide fast scram action to minimize the fissions occurring in Skua immediately following the burst. In the case of Godiva, the fast scram is triggered automatically (in addition to electrically) by a "block-bounce" phenomenon associated with rapid expansion of the fuel. We will trigger a fast scram in Skua at low radiation levels using a plastic scintillator-photomultiplier radiation detector. Because of the approximate 10-fold slower time scale for Skua, the scram action need not be as rapid as for Godiva. The design of Skua does not lend itself to the block-bounce type of fast scram boost.

Instrumentation for routine measurements of the length of the prompt period consists of a plastic scintillator-photodiode radiation detector and a timing circuit for measuring the rate of rise of the signal. Provided that preinitiation has not occurred, the initial period (before any significant generation of heat) supplies a direct check of the reactivity setting for the burst.

We will display the burst shape on an oscilloscope and photograph it for permanent record. The half-width of the radiation spike is a measure of initial period. (Provided that preinitiation has not occurred.) Furthermore, the spike amplitude is a check of relative yield. The plastic scintillator-photodiode combination serves as the detector for this burst shape display.

The neutron monitoring instrumentation used with Skua is the standarc system used with other Kiva assemblies. It normally includes two or more log response scram monitors and one or more linear dc amplifiers using $\mathrm{BF}_{3}$ ion chambers. Pulse counting with $\mathrm{BF}_{3}$ proportional counters is routinely used to monitor low neutron levels. The linear amplifiers are read out on strip chart recorders. 


\subsection{Reactor Trip System}

The discussion of the reactor trip system in LA-6206' is applicable to Skua. In addition to the conventional reactor trip system discussed in that report, the fast scram described in the preceding section of this report is used to minimize the amount of radiation following a burst. The fast scram does not contribute to safety except as it supplies additional redundancy in scram initiation.

The three safety blocks are operated hydraulically. A separate hydraulic accumulator on each safety block provides stored gas-pressure energy sufficient to scram the blocks in case of hydraulic pump or power failure. To reset the control system, hydraulic pressure and gas pressure are required to be at proper levels. (Pressure switches are wired to the interlock system.) Safety-block control and scram make use of relay-operated solenoid valves. A schematic of the hydraulic system is shown in Fig. 5-1. One safety block is shown with a separate control for stopping the block in any position. This feature was included for safety-block worth measurements during initial critical experiments and will not be used in the burst mode. Furthermore, this additional cortrol does not affect the scram action of the block.

A leak in the hydraulic system will reduce hydraulic pressure at one or more of the hydraulic accumulators.
As soon as pressure drops below the pressure switch setting on the hydraulic side of the accumulator, all three safety blocks will scram. Regardless of the pressure from the pump, the accumulator gas pressure is adequate to complete scram action. Check valves isolate each safety-block cylinder and its accumulator from leaks toward the hydraulic pump unit and prevent lines from draining if a leak should develop in the common line from the hydraulic pump unit. Thus, the accumulators transmit their pressure to the hydraulic cylinders and not to the leak. Simultaneous leaks near all three hydraulic actuating cylinders would be required to prevent an adequate scram.

The "in" position of the safety blocks is determined by a positive mechanical stop at the end of the hydraulic cylinders, and the blocks are not permitted to touch the core. "In" and "out" limit switches are wired to the interlock system, permitting these positions to be indicated by lights on the control panel. The limit switches, however, are not precise enough to confirm the safety block "in" position with high accuracy. Reproducibility of position is verified by intercomparison of delayed-critical checks; operations thus far show no evidence of safety-block irreproducibility.

The Skua logic diagram in Fig. 5-2 illustrates the interaction between the control system, the control interlocks, and the scram chain.

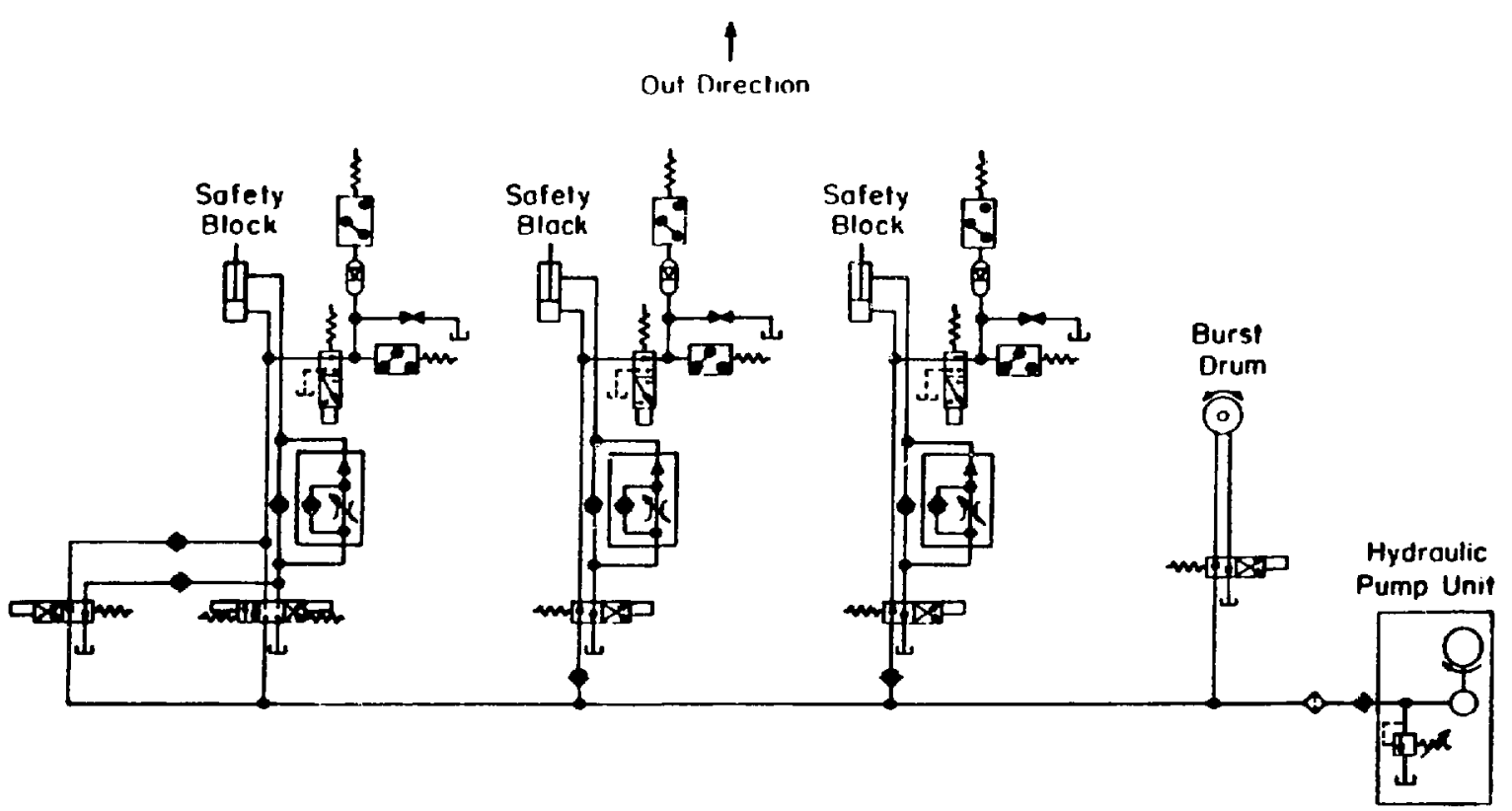

Fig. 5.1.

Skua hydraulic control system. 


\subsection{Engineered Safety Systems}

Not applicable.

\subsection{Systems Required for Safe Shutdown}

The discussion of safe shutdown systems in LA $-6206^{1}$ is applicable to Skua. In addition to that report, as stated in Sec. 5.2 here, the independent accumulator on each safety block assures fail-safe shutdown in case of malfunction or power failure. The control drums provide some redundancy because they are adequate to shut the system down safely even if the safety blocks do not scram.

\subsection{Safety-Related Display Instrumentation}

The discussion of safety-related display instrumentation in LA-6206 ${ }^{1}$ is applicable to Skua.

\subsection{All Other Systems Required for Safety}

The discussion of all other safety systems in LA-6206' is applicable to Skua.

\subsection{Control Systems}

The three control drums, designated delayed critical, yield adjustment, and burst, are identical and, as indicated in Fig. 3-6, measurements show their normal

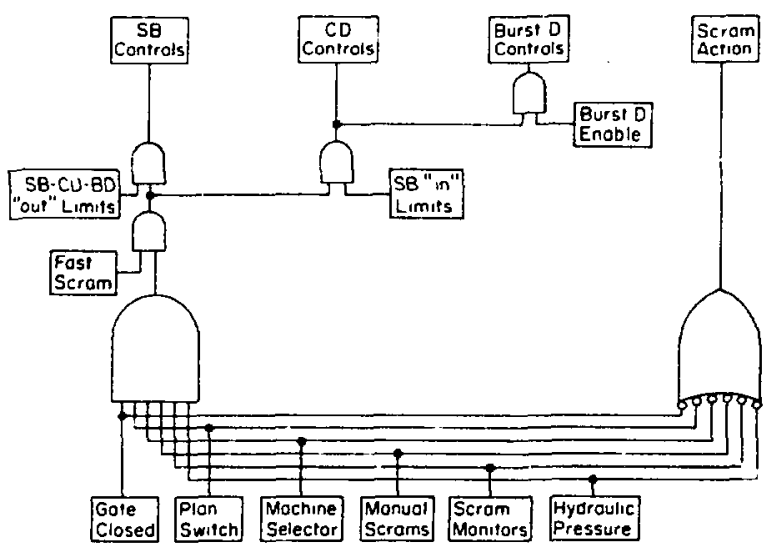

Fig. 5.2.

Scram-chain logic for Skun; SB is safety block, $\mathrm{CD}$ is control drum (delayed critical and yield adjustment) and BD is burst drim. worth to be $\sim 2.7 \$$ (each) for their full $180^{\circ}$ range. Varnier control is by the delayed-critical and the yield-adjustment drums. Actuation is by means of stepping motors, which are used with $60-\mathrm{Hz}$ power at a single speed. This speed is limited to $0.05 \$ / \mathrm{s}$ by our Technical Specifications. Accurate positioning can be obtained by "jogging" the centroller. The shafts of the vernier drums are coupled by a magnetic clutch to the driving motors. The actuators are spring loaded so the drums will return to their "out" positions when the magnetic clutch is de-energized. Scram of these two drums is then by spring action, providing fail-safe response to a power failure. The control system for the vernier drums is shown in Fig. 5.3. The "in" and "out" limit switches for all the drums are incorporated into the interlock system. The range of the yield-adjustment drum will be restricted by positive stops or limit switches which establish the "in" and "out" positions of the drum.

The burst drum is operated hydraulically from the safety-block hydraulic unit as shown in Fig. 5-1. The high speed of this drum $(\sim 10 \mathrm{~S} / \mathrm{s})$ combined with its large mass makes a special slow-down mechanism necessary: shock absorbing stops act directly on the drum so that little stress is transmitted to the drive system. Figure 5-4 shows the stopping mechanism. The burst drum is scrammed hydraulically following a signal from the fast-scram detector. The burst-drum range will be set at a nominal $1.5 \$$. Its precise value is not important inasmuch as the burst yield is independent of the value. There are two concerns with the burst drum: (a) its "in" position must be the same for the delayed-critical check and the burst condition and (b) the drum must not rotate beyond its geometrical $0^{\circ}$ position when it is inserted in order to avoid a reactivity peak

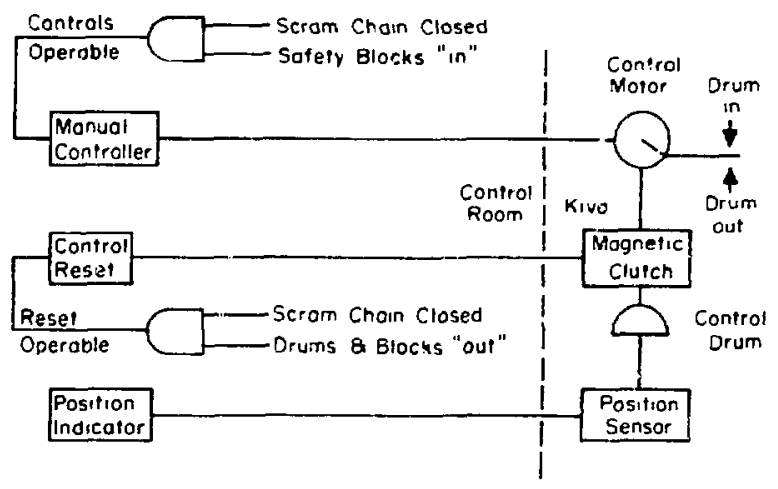

Fig. 5.3.

Control logic for Skua. 


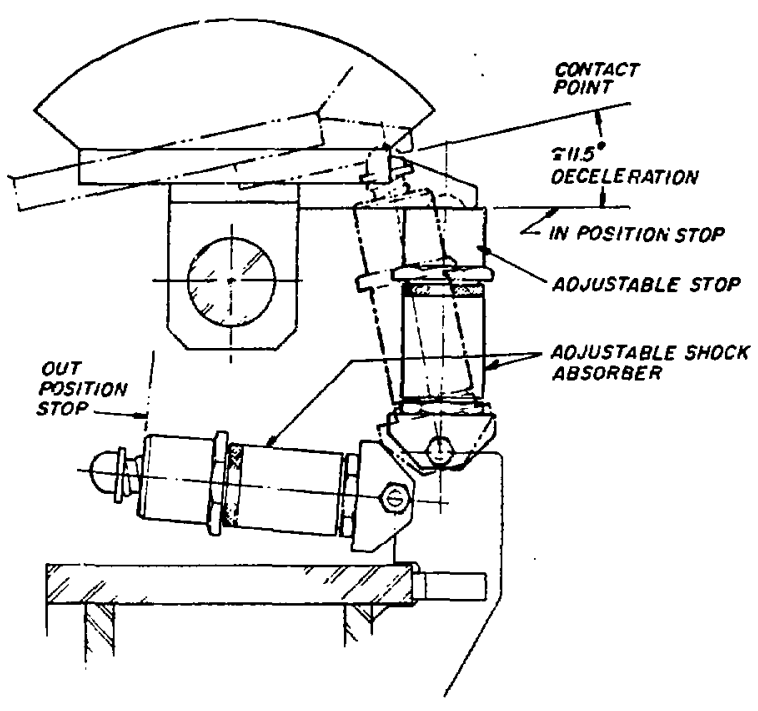

Fig. 5.4 .

Burst-drum stopping mechanism.

$t$-fore seating. Such a malfunction could result in excess yield in case of preinitiation. Both (a) and (b) are assured by the combination of a rugged positive stop mechanism and the Precision Angle Indicator position read-out. Every operation of the burst drum provides a check of the position of its positive stops.

Precision Angle Indicators (Superior Manufacturing and Instrument Corporation) are used on the delayed-critical, yield-adjustment, and burst drums to read out angular position to $0.02^{\circ}$. These indicators have been used at LASL for many years on various critical-assembly machines, and they have proven to be accurate and reliable. The synchro transmitter is coupled directly to the drum shafts rather than to the actuators so that there is no possibility of slippage or backlash. Analog position indicators, also mounted on the three drum shafts, serve as back-ups to the primary angle-indicating instrumentation. The burst drum has in-out control only, and the Precision Angle Indicator provides an accurate check of the position of its positive stops.

The flux trap is attached to a motor-driven lift for remote removal from the core. A "down" limit switch must be actuated to allow the controls to be reset. The lift will be operated only following a burst, and hence its presence will not contribute to any uncertainty in burst yield.
Interlocks for Skua operation require that all drums and blocks be at their "out" limits to permit the controls to be reset. Figures 5-2 and 5-3 show the other interlocks. The requirements for operation are

(1) Plan switch set on Plan 3.

(2) Machine selector on "Skua."

(3) Gate-closed switch activated.

(4) Manual scrams reset.

(5) Scram monitor reset.

(6) Hydraulic pressure and accumulator gas pressure in the operating range.

(7) Fast scram reset.

(8) Safety blocks and control drums "out."

(9) Flux trap lift "down."

When these requirements are satisfied, the machine controls can be reset and the sufety blocks inserted. The control drums can be operated only when the safety block "in" limit switches have been actuated. Finally, for burst operation a special enable switch must be closed to allow the burst drum to be inserted. The spring-loaded switch returns to its normally open position when released. Inadvertent operation of the burst drum would not represent a hazard, but it would defeat coordination with experiments associated with burst production.

\subsection{Power Systems}

The discussion of power systems in LA- $6206^{1}$ is applicable to Skua.

\section{AUXILIARY SYSTEMS}

\subsection{Fuel Storage and Handling}

Because the fuel rings in Skua are inaccessible, we plan to store the material in place even if the assembly is not in use. Any extra fuel will be kept in the Kiva 3 vault.

\subsection{Fire Protection System}

The discussion of the fire protection system in LA-6206. ${ }^{1}$ is applicable to Skua.

\subsection{Communication System}

The discussion of the communication system in LA-6206 ${ }^{1}$ is applicable to Skua. 


\section{EXPERIMENTS: DESCRIPTION AND PURPOSE}

The major experiment with Skua is that of bringing it up to the burst mode of operation and investigating its behavior for various pulse yields. As mentioned in Sec. 1.1, some experiments will vaporize uranium foils or compounds in the flux trap by the fission energy developed. The extremely high, slow-neutron flux available will stimulate many experiments directed at nuclear pumping of lasers and overpower failure of power-reactor fuel elements. Other applications are associated with the nuclear weapons program. Any experiment, either in the burst mode or the delayed-critical mode, must be covered by an Experimental Plan in addition to this SAR. Thus, any special problems associated with an experiment, such as containment or movement of materials in the flux trap, will be subject to independent review.

Generally, after the initial experiments, irradiation investigations will be relatively routine; however, if any of these present new safety considerations, Experimental Plans will describe their execution in accordance with the requirements of "Operating Procedures for the Pajarito Site Critical Assembly Facility."

Other experiments will involve variation in Skua geometry aimed at tailoring the central neutron spectrum to a specific requirement. This will involve adjusting the moderator content in the flux trap. One of Skua's attractive features is the possibility of providing a very thermal or a very high-energy neutron field in the burst mode. Potentialiy, neutron fluxes between these two extremes may be useful. Reactivity adjustment to accommodate variations in flux-trap moderators will be achieved by reducing the number of fuel rings or modifying the uranium carbide annulus. During the preliminary critical operations of Skua, experiments were run with reduced fuel and without a flux trap.

In general, the approach to burst operation with modified flux traps is no different than that presented in this SAR. Differences in neutronic properties will be established by critical measurements before the approach to prompt critical. A boron-containing annulus must be present for all Skua geometries. With reduced moderator the absorber isolates the effect of experiments in the cavity from the fuel.

Calculations show that flux traps with small quantities of hydrogenous moderator add reactivity to the system, whereas "larger" flux traps act as a poison. The maximum reactivity added by the moderator appears to be $\sim 3$. The 56-mm-thick polyethylene moderator in the present Skua design contributes $-14 \$$ of reactivity (-8 $\$$ measured for the complete flux trap). Moderators in the cavity inay increase or decrease reactivity of the system depending upon the amount of moderator in the flux trap. For any systern it is important that experiments in the cavity not be allowed to shift and perturb reactivity during operation. Skua without a flux trap present has characteristics similar to those of Godiva; however, bursts will be wider because of the effect of the copper reflector on the neutron lifetime.

In addition to the procedures specified in this SAR, the following requirements shall apply to burst operation of Skua with a modified flux trap."

(1) An Experimental Plan shall be written covering operations of Skua with a modified flux trap.

(2) Burst operation with a modified flux trap shall be preceded by critical experiments establishing the neutronic characteristics of the modified system.

(3) All Skua burst geometries shall contain a boron absorber shell, reducing the interaction of material in the cavity with neutronic behavior.

\section{RADIOACTIVE WASTE MANAGEMENT}

Other than direct radiation, no radioactivity associated with Skua bursts will be detectable outside the Kiva. Some minor contamination inside the building will result from oxidized uranium dust and fission-fragment dispersal. The contamination is kept within tolerable limits by our routine housekeeping activities.

\section{RADIATION PROTECTION}

The discussion of radiation protection in LA- $6206^{1}$ is upplicable to Skua.

\section{PROCEDURES FOR BURST PRODUCTION}

Operating procedures for Pajarito Site critical assemblies are specified in Ref. 4 and apply to Skua operations. They include required preoperational checks,

\footnotetext{
-A modified flux trap shall be considered one containing less hydrogen than in the zirconium hydride annulus used in the preliminary Skua critical experiments (hydrogen density 0.08 $\mathrm{g} / \mathrm{cm}^{3}$ and $56 \mathrm{~mm}$ thick).
} 
precautions for local and remote operation, and instrumentation requirements. The approach to prompt critical will be by steps, starting with positive period measurements in the region between delayed and prompt critical and graduaily increasing the reactivity into the prompt-critical region. We have modeled the operation of Skua after that of Godiva, which has proven to be reliable and effective over many years of burst production.

The burst drum is inserted rapidly to produce a burst. It is appropriate to have a burst-drum reactivity increment somewhat over a dollar. The yield-adjustment drum is used to set the size of the burst, and the delayed-critical drum is adjusted to obtain the preburst critical check. A supercritical configuration is obtained by first establishing a delayed-critical condition with the burst drum "in" and the yield-adjustment drum at a predetermined setting, $\theta_{y_{A}}$. Then, when the yield-adjustment drum is rotated to its fully "in" position, an excess reactivity is established equal to the increment added by the yield-adjustment drum in moving from its delayed-iritical position to its "in" position. In practice it is desirable to establish the supercritical condition rapidly and with no significant neutron population present; therefore, following the delayed-critical check the burst drum is rotated to its "out" position and one or more safety blocks are removed, allowing the delayed-neutron level to decay for about $20 \mathrm{~min}$. At this time the burst is produced by rotating the yield-adjustment drum to its "in" position, restoring the safety blocks, and inserting the burst drum rapidly. Thus, the critical configuration is reproduced with the exception of the yield-adjustment drum, which has added reactivity, $\Delta \mathrm{k}_{\mathrm{YA}}$, corresponding to its change in position from $\theta_{Y A}$ (at delayed critical) to its "in" position.

This procedure for obtaining the excess reactivity $\Delta \mathrm{k}_{\mathrm{YA}}$ rapidly, will be carried out in the region between delayed and prompt critical, and then continued in small steps into the superprompt critical region. Again, it is important to point out that the details of this experiment will be described in an Experimental Plan. The experiment summarized above provides a reactivity calibration of the yield-adjustment drum and a calibration of the burst yield in terms of the yield-adjustment drum position during the delayed-critical check. The latter calibration in the form of a plot of yield vs yield-adjustment drum position serves as the most important data for routine burst production. The range of the yield-adjustment drum will be limited by either positive stops or limit switches. (Manual adjustment of the range will be possible at the Kiva.) In initial prompt-critical measurements, reactivity increments above prompt critical shall be no larger than $0.02 \$$ and the range limit will be set within $0.05 \$$ of a previously checked buist. As burst yield is increased by steps, the yield-adjustment drum range limit will be adjusted to limit the maximum possible error in setting. For routine operation with known geometries, the range limit will be set to correspond to the largest yield desired; thus, the requirements on the yield-adjustment range settings are designed to limit the reactivity that can be achieved by operator error or equipment malfunction. Control-drum settings for burst operation shall be checked independently by two crew members. The maximum worth of the yield-adjustment drum is expected to be $\sim 1.3 \mathrm{~s}$. The angle read-out instrumentation, as in the case of the burst drum, provides a continuous check of the available drum increment.

Any experiment in the flux-trap cavity that changes Skua ieactivity significantly can be expected to affect the relationship between burst yield and yield-adjustment drum settings, and repeating part of the calibration procedure described above may be necessary to establish a corrected curve. To a ssess the perturbation induced by an experiment in the flux trap (or in the vicinity of Skua), a check of the yield-adjustment drum worth will be made by a reference positive period in the region from $0.5 \$$ to $1.0 \mathrm{~S}$ above delayed critical. This calibration check will be required for any experiment that changes the basic reactivity by $0.2 \mathrm{~s}$ or more. For such new experiments a calibration curve of burst yield vs yield-adjustment drum reactivity shall be established in a manner similar to the initial approach to burst operation. Check points above prompt critical shall proceed in increments not exceeding $0.05 \$$ until the desired burst size is reached. For these calibration experiments, as with the initial approach to prompt critical, the yield-adjustment drum's available reactivity shall not exceed by more than $0.05 \$$ the reactivity of a previous'y checked burst. Comparison of the new calibration data with the standard calibration curve will allow extrapolation in $0.05 \$$ increments to be made with confidence.

The step-by-step procedure for producing routine bursts is summarized below.

(1) Criticality Check. With the burst drum fully inserted, we adjust the delayed-critical drum until a stable critical condition is achieved. The yield-adjustment drum for this critical check is set at a value that has been calibrated to result in the desired yield. For example, if a $0.1 \$$ superprompt 
critical burst is desired, the $\Delta \mathbf{k}$ for the yield-adjustment drum from its setting at critical to its setting during the burst (fully. in) will be 1.10 \$. As with Godiva, we require that the drum settings for burst operation be determined independertly by two crew members.

(2) Delayed Neutron Decay. We withdraw the burst drum to its "out" position and withdraw one or more safety blocks. We allow the neutron level to decay to its background value. This requires about $20 \mathrm{~min}$. If the neutron level is too high, preinitiation will result while the burst configuration is being established.

(3) Reactivity Adjustment. We run the yield adjustment drum to its fully "in" position. This will increase reactivity by an amount equal to the l'eactivity desired for the burst. Just before the burst the safety blocks will be reinserted. Since the delayed-critical drum is untouched following the criticality check and the remaining drums are "in" at burst time, it is only the reproducibility of the "in" positions that governs the reproducibility of burst reactivity. The magnitude of the burst is determined by the position of the yield-adjustment drum at the delayed-critical checkpoint.

(4) Burst. We insert the burst drum to produce the burst. This drum must be capatle of insertion in a fraction of a second to avoid preinitiation.

The advantage of the procedure described above is that except for an incorrect setting of the yield-adjustment drum for the delayed-critical check, only the "in" position of any drum can affect the burst, and any deviation from the normal "in" position is quite likely to be in the direction of decreasing the yield. Various postulated accident sequences are presented in the succeeding sections.

\section{ACCIDENT ANALYSIS}

\subsection{Hazards Summary}

Calculations and measurements show that a yield of $10^{19}$ fissions in one of the Kivas is required to give a whole-body dose of $3 \mathrm{rem}$ at the exclusion area entrance for a normal critical operation. The "Kinglet Safety Analysis" (LA-4797-MS) ${ }^{2}$ concludes that the release of all gaseous fission products from a 10 -s run of $1.3 \times 10^{18}$ fissions under the most adverse atmospheric conditions produces doses less than $5 \mathrm{rad}$ to the whole body or 20 rad to the thyroid at $300 \mathrm{~m}$. Based on these estimates the "Technical Specifications for the Pajarito Site Critical Experiments Facility" specifies a safety and an operating limit. ${ }^{3}$ The operating limit is the fission integral that results in fission-product power generation of $600 \mathrm{~W}$ when averaged over the first hour after shutdown. For a burst the limit corresponds to $10^{18}$ fissions. The safety limit corresponds to a Kiva operation that generates a wtal of $10^{19}$ fissions within $1 \mathrm{n}$. From the practical point of viev, no significant hazard exists until the site safety limit is sxceeded. On the other hand, a yield of $10^{18}$ fissions in a Godiva burst would destroy the assembly. In the case of Kinglet, a yieid greater than $10^{18}$ fissions would have teen possible without damage. Clearly, it is most important to avoid exceeding both the yield which will damage an assembly and the safety limit. In Skua the damage threshold corresponds to about $3 \times 10^{17}$ fissions in a burst, and partial melting would occur with $10^{18}$ fissions.

\subsection{Conceptual Accidents}

One can generate various scenarios for Skua that would lead to inadvertent reactivity changes and hence, potentially, to excessive fission yields. These could result from operator error, assembly malfunction, or shifting of some Skua component or part of an experiment during operation. Certain of these hypothetical events can be ruled out on the basis of probability and others can be ruled out because of procedural requirements. In any case, it is appropriate to examine such occuriences to determine what measures are required to assure reliable operation and whether a significant hazard is inherent in Skua burst operation.

(1) Operator Error. In this example the operator missets the yield-adjustment drum during the preburst critical check. This type of error is unlikely because previous experience would tend to alert the operator to any serious deviation in critical condition. We will use a graph of burst yield vs yield-adjustment drum position to establish the proper setting for the desired yield. We will limit the reactivity available with this drum, hence the possible accident consequences will have an upper boundary. As stated in Sec. 10, the drum settings for burst operation will be determined independently by two crew members.

There is an additional operator error that could result in a large burst yield in the absence of appropriate interlocks. We have considered the 
possibility that in the final assembly step, just before inserting the burst drum, the operator inadvertently runs in the delayed-critical drum instead of the yield-adjustment drum. The reactivity added by the delayed-critical drum in certain circumstances could be much larger than that added by the yield-adjustment drum in the proper mode of operation. To avoid this possibility, the delayed-critical drum is interlocked to prevent inward motion when the burst drum is withdrawn. This eliminates any possible increase in reactivity by the delayed-criticai drum between the delayed-critical check and the burst-drum insertion.

(2) Equipment Malfunction. Equipment malfunctions that lead to an incorrect setting of the yield-adjustment drum would result in a corresponding error in the burst yield. We will require that the yield-adjustment drum be equipped with two independent, position-indicating instrumentation systems; therefore, an unambiguous incorrect setting would require two simultaneous failures. Furthermore, a significant error in the yield-adjustment drum setting would be reflected in anomalous delayed-critical check conditions and would indicate to the operator that something was not normal.

The "in" positions of the burst drum and the yield-adjustment drum are fixed by positive stops. If these stops shift, the burst yield will be affected; however, near the "in" position, either drum can move several degrees without changing reactivity by more than $0.01 \$$. The Precision Angle Indicators show the position of the positive stops to within a small fraction of a degree.

Should one of the safety blocks stick during the preburst check and subsequently function properly when reinserted at burst time, there would be a larger yield than planned. The magnitude of this type of malfunction is restricted by the "in" limit switch on the safety blocks. Interlock logic requires that these limit switches be actuated before the control drums can be operated. The reproducibility of delayed-critical checks provides continuous monitoring of the reproducibility of safety-block seating.

If the safety blocks snould fail to scram as a result of some common mode failure in the scram system, the power following a burst will remain at a higher than normal level owing to the high multiplication of delayed neutrons. If this malfunction were to occur following a high-level burst, higher than desirable temperatures in Skua would result. Scram action of the burst drum, the yield-adjustment drum, and the delayed-critical drum serves to mitigate the effect of safety-block failure. These three drums receive their scram signal from the "fast-scram" detector and are actuated by a separate scram relay; hence, they are completely isolated from a common mode failure in the normal scram chain. As stated in Sec. 5.7, the yield-adjustment and the delayed-critical drums scram under spring action following the release of a magnetic clutch.

Common mode failure on the hydraulic side of the safety blocks is inconceivable because of the separate accumulators and pressure switches used for each safety block.

If we assume failure of the safety blocks and a total scram contribution of $3 \$$ for the three control drums, burst yield will be increased by less than $50 \%$. Although the resulting temperature would be higher than expected, safety-block failure is not considered a serious accident.

(3) Shifting of Equipment. With the flux trap in place, most materials inside are expected to have little effect on reactivity. For fissionable materials and neutron poisons this is not the case, and a serious accident could result if an experiment were to shift between the delayed-critical initial check and the burst. To counteract this possibility we will require that an Experimental Plan be written to explain what protection is provided to assure stability whenever the test geometry contributes significant reactivity. Lateral shifting of the uranium rings relative to the flux trap and the copper reflector is limited by the sinall space between the components, and this small movement does not induce a significant reactivity change. Furthermore, the fuel rings are keyed to the support stand and fastened by a clamping ring and large bolts.

(4) Hydrogen Loss from the Flux Trap. Because reactivity increases as hydrogen is removed from the flux trap, hydrogen loss during a burst could boost the yield. Instantaneous heating by neutron and $\gamma$-ray interactions in the moderator is not significant. Heat transfer from the fuel rings to the moderator through the cadmium and the boron is too slow to be effective until after the reactor has 
scrammed following a burst. Even melting of polyethylene moderator would hardly affect reactivity since it is confined in the flux-trap container. Zirconium hydride requires a high temperature to release its hydrogen, and there is no mechanism for raising its temperature that high. In the case of an accident, the lag in moderator temperature rise associated with conduction from the fuel rings guarantees that the accident will be terminated before loss of hydrogen can contribute reactivity to the system.

Initial experiments in the burst mode will be made with the zirconium hydride moderator cylinder. This material does not begin to lose hydrogen until its temperature reaches $375^{\circ} \mathrm{C}$, therefore, loss of hydrogen is not a concern. If burst experiments are to be conducted with a polyethylene flux trap, safety problems will be reviewed in an Experimental Plan. Flux-trap temperatures vill be monitored with one or more thermocouples. The heat distribution calculation shown in Table 11-1 (See also Fig. 3-8.) is based on the heat capacities of the fuel and the flux-trap components and heat losses to the reflector and the environment do not enter into the caiculation. The burst considered is an extreme one, corresponding to an average temperature rise oi $400^{\circ} \mathrm{C}$ in the fuel rings (>3 $\times 10^{17}$ fissions). Considering actual heat losses, the temperature rise in the flux trap would be much less than $185^{\circ} \mathrm{C}$.

\section{TABLE 11-I}

\section{TEMPERATURE RISE IN THE FLUX TRAP}

\begin{tabular}{|c|c|c|c|c|}
\hline \multirow[b]{2}{*}{ Material } & \multirow{2}{*}{$\begin{array}{c}\text { Weight } \\
\text { (kg) }\end{array}$} & \multirow{2}{*}{$\begin{array}{c}\text { Specific Heat } \\
\left(\mathrm{cal} / \mathrm{g}-{ }^{\circ} \mathrm{C}\right)\end{array}$} & \multicolumn{2}{|c|}{$\begin{array}{c}\text { Temp Rise } \\
\left({ }^{\circ} \mathrm{C}\right) \\
\end{array}$} \\
\hline & & & Initial & Final \\
\hline U-Mo fuei & 174.5 & 0.035 & 400 & 185 \\
\hline Al can & 0.57 & 0.215 & $\ldots$ & 185 \\
\hline$U C_{100}$ & 4.65 & 0.170 & 15 & 185 \\
\hline Boral & 3.20 & 0.218 & 15 & 185 \\
\hline Cd & 1.17 & 0.554 & $\cdots$ & 185 \\
\hline $\mathrm{ZrH}$ & 28.7 & 0.134 & 5 & 185 \\
\hline Graphite & 0.33 & 0.170 & $\cdots$ & 185 \\
\hline
\end{tabular}

A shift in position of the flux trap would perturb reactivity; however, a lateral shift of the components is limited and can have little effect. Inasmuch as the flux trap rests on the same supports as the fuel rings, we do not believe that vertical misalignment is a problem.

(5) Loss of Poison from the Flux Trap. Because neutron absorptions in the cadmium and boral components of the flux trap result in a large negative reactivity contribution, loss of this poison during a burst would be undesirable. To lose boron the aluminum matrix would have to melt. allowing the boral cylinder to slump. Calculations show that normal operations will not result in enough energy deposition in the boron to cause melting. Furthermore, the cadmium buffer is effective in eliminating the high thermal-neutron absorption spike in the boral. Little energy is deposited in the cadmium when neutrons are absorbed because this absorption results in an energetic $\gamma$-ray: therefore, cadmium melting cannot occur promptly. There appears to be a negligible chance that poison loss can result in a boosting of the burst yield.

(6) Improper Seating of the Fuel Rings. If thermal shock during a burst were to shift the fuel rings to a higher density stacking, the resulting reactivity gain wo id increase the burst yield. We will ininimize this possibility by carefully comparing leference reactivities following any disassembly and reassembly. Since the fuel cylinder is held together by bolts, the geometry cannot change once the correct fit has been achieved. In any case, the routine delayed-critical checks would readily detect any change in seating of the fuel rings. We do not consider fuel-ring shifting to constitute a significant hazard in Skua operation.

(7) Inadvertent External Reflection. External reflection is of concern if (a) it is sufficient in magnitude to compromise the shutdown margin or (b) it adds reactivity that affects the burst yield. The magnitude of external reflection is limited by the presence of the 3-in. copper reflector and the structure surrounding it. Bolts for the clamp ring and massive supports for the safety blocks and control druris make it physically impossible to bring large jieces of material close to the reflector. 
More than one-hali of the copper reflector is moved out of position by the safety blocks and the control drums. It is inconceivable that an inadvertent reflector could approach the effect of this scrammed reflector and thereby compromise the shutdown margin. The effect of personnel in proximity to the reflector and the core was monitored when flux wires were being installed about the fuel rings during initial operations. Observation of multiplied counting rates showed no apparent increase for this operation, indicating that the added reactivity vas a small fraction of the shutdown margin.

In the case of concern (b) above, the delayed-critical check would detect any significant change in reflection, and even if extra reflection were present, the burst yield would not be affected unless reflection conditions changed between the delayed-critical check and the burst.

We do not consider inadvertent external reflection to be a potentially perturbing influence on burst yield.

\subsection{Design Basis Accident}

We consider the Design Basis Accident (DBA) to be an incident resulting from improper setting of the yield-adjustment drum either through operator error or equipment malfunction. Other potential accidents discussed in Sec. 11.2 have either been shown to be of low probability or are susceptible to control by administrative action. We arbitrarily will choose the DBA as at burst of $10^{18}$ fissions in Skua, which is sufficient to destroy the assembly functionally, but which will not evaporate uranium or produce significant effects outside the Kiva. We will establish conditions and administrative procedures to assure that $10^{18}$ fissions cannot be exceeded in this accident. The limit of $10^{18}$ fissions for the DBA has been selected to allow as much flexibility as possible in the operation of Skua without presenting a significant hazard to personnel or the potential for damage to the site.

We will establish the upper boundary to the DBA by limiting the amount of reactivity available with the yield-adjustment drum. This will be achieved either by design of the drum or by mechanical or electrical positive stops. The burst drum reactivity will have a fixed value, probably about $1.5 \mathrm{\$}$, as with Godiva IV. This large value is essential to avoid excessive neutron level build-up during the final assembly. Since reactivity is measured with the burst drum "in," only uncertainties in its "in" position will influence the size of the burst. The yield is entirely a function of the yield-adjustment drum position during the delayed-critical check. For the bt rst, this drum is moved from its delayed-critical position to its "in" position. The burst then corresponds to a reastivity above delayed critical equal to the increment provided by the yield-adjustment drum in rotating from its position during the critical check to its "in" position. We will limit the range of the yield-adjustment drum to that which gives a reactivity increment producing a burst of $<10^{18}$ fissions when this reactivity is added to the delayed-critical condition; that is, the delayed-critical and bursi configuration for the extreme burst would be as follows.

\begin{tabular}{lcc} 
& $\begin{array}{c}\text { Delayed } \\
\text { Critical }\end{array}$ & Burst \\
\cline { 2 - 3 } $\begin{array}{lc}\text { Delayed-critical drum } \\
\text { Yield-adjustment drum }\end{array}$ & $\begin{array}{c}\theta_{\mathrm{dc}} \\
\text { "out" }\end{array}$ & $\begin{array}{c}\theta_{\mathrm{dc}} \\
\text { "in" } \\
\text { Burst drum } \\
\text { "in" }\end{array}$ \\
"in" $<10^{18}$ fissions & &
\end{tabular}

In the data above, "out" for the delayed-critical position of the yield-adjustment drum refers to the extreme position permitted by the range adjustment setting. The value $\theta_{d c}$ is the delayed-critical drum position at the delayed-critical checkpoint. To obtain a yield of $10^{18}$ fissions would require that the yield-adjustment drum range limit be set incorrectly. Since the delayed-critical drum is not moved between the delayed-critical check and the burst, neither the magnitude of its reactivity range nor the precision with which its position can be determined are important factors in accident considerations.

The engineered safeguards and administrative procedures that have been established to limit the probability of serious accidents are summarized below.

(1) The burst-drum range is established by rugged positive stops with confirmation by Precision Angle Indicator instrumentation.

(2) The yield-adjustment drum range shall be established by positive stops or limit switches with confirmation by Precision Angle Indicators. Adjustment of the range limit shall be possible only at the Kiva.

(3) The delayed-critical drum is interlocked to prevent in-motion when the burst drum is not "in."

(4) For initial operations above prompt critical, successive increments in reactivity shall be limited to 
0.02 \$. The yield-adjustment range limit shall be set within $0.05 \$$ of a previously checked burst.

(5) Calibration of the yield-adjustment drum shall be checked for any new experiment that affects reactivity by as much as $0.2 \mathrm{~s}$.

(6) Control-drum settings for burst operation shall be checked independently by two crew members.

(7) The approach to prompt critical and the procedure for conducting new experiments shall be specified in an Experimental Plan subject to independent review.

At this writing we are unable to establish the relationship between burst yield and reactivity, because Skua reactivity quench characteristics are not known and can be determined with certainty only by experiment. In this regard. the experiments to be conducted in approaching the burst mode of operation (mentioned in Sec. 10) will determine these required dynamic quench characteristics. Extension into the self-limiting burst region is essential for this determination. Excess reactivity corresponding to a $10^{18}$ fission burst will be deduced by extrapolation of test results through previously validated accident computing codes.

The effectiveness of the yield-adjustment drum may vary significantly for different experiments in the flux-trap savity. Fissionable materials in the cavity will have the greatest effect on reactivity and the dynamic characteristics of Skua. Thus, as experiments change, the yield-adjustment drunı range will have to be modified so that the DBA limit will noi exceed $10^{18}$ fissions.

Thus, the maximum DBA corresponds to a burst for which the yield-adjustment drum has been at its "out" limit for the delayed-critical check and then is run to the fully "in" position for burst production. It is unlikely that this outer position will occur inadvertently, because it is a singular position and as such would come to the attention of the operators. Furthermore, we should emphasize again that the DBA limit would still not be approached without a significant error in the setting of the yield-adjustment drum, which is possible only if the range limit has been adjusted incorrectly. Such an error would result in a corresponding anomalous delayed-critical check, which would be apparent. Consequently, the DBA is unlikely to result in the extreme yield of $10^{18}$ fissions.

Doses are discussed for a Godiva accident in LA-6206, Vol. II. Sec. 4.2.1, ${ }^{1}$ where it is stated that a whole-body dose of $0.06 \mathrm{mrem}$ results at $500 \mathrm{ft}(150 \mathrm{~m})$ from the Kiva for a Godiva excursion of $1.2 \times 10^{17}$ fissions. A reasonable extrapolation to Skua would be simple scaling to a $10^{18}$ fission burst, since the fissionable material is metal in both cases. The resulting dose prediction of $<1 \mathrm{mrem}$ is completely negligible.

The Kinglet calculation for a $1.3 \times 10^{18}$ fission accident assumed no gaseous fission-product retention in the solution and took no credit for retention in the Kinglet building. As would be expected, the Kinglet dose is many orders of magnitude higher than the Godiva or Skua dose.

In summary, for the design basis accident in Skua, fission-product retention in the metal core (even if partially melted), combined with retention and delay afforded by the Kiva, assures that no sigrificant on-site or off-site dose will result.

\section{QUALITY ASSURANCE PROGRAM}

The discussion of the quality assurance program in LA- $6206^{1}$ is applicable to Skua.

\section{REFERENCES}

I. H. C. Paxton, "Safety Analys's of the Los Alamos Critical Experiments Facility," Los Alamos Scientific Laboratory report LA-6206, Vol. I (February 1976), Vol. II (August 1976).

2. T. F. Wimett, R. H. White, H. C. Paxton, and J. D. Orndoff, "Kinglet Safety Analysis," Los Alamos Scientific Laboratory report LA-4797-MS (October 1971).

3. H. C. Paxton, "Technical Specitications for the Pajarito Site Critical Experiments Facilty," Los Alamos Scientific Laboratory report LA-6016-SOP (Noveinber 1975).

4. J. D. Orndoff and H. C. Paxton, "Operating Procedures for the Pajarito Site Critical Assembly Facility," Los Alamos Scientific Laboratory report LA-4037-SOP, Rev. I (January 1973). 